\title{
Establishment and Development of Cultivating Base of Postgraduates with Professional Degree by University- Enterprise Cooperating
}

\author{
Bin Xu Aijun Tang Xiaohong Fan Hailong Ma \\ College of Materials Science and Engineering in Shangdong Jianzhu University, Jinan, \\ Shandong Province, China
}

\begin{abstract}
In order to change the practical and innovation ability inadequacy of postgraduates with professional degree under traditional cultivating mode, this paper attempts to improve the postgraduates' practical and innovation ability through establishing the university-enterprise cooperated cultivating base for postgraduates. Through the mode of putting forward a subject by the enterprise and studying the subject by entering the cultivating base with the guidance of a tutor, the postgraduates' practical and innovation abilities of solving problems are cultivated. On the base of conventional teaching system, academic activities such as the academic reports, technical seminars, postgraduates' achievements showing and innovation competitions are carried out regularly to cultivate the overall qualities of the postgraduates with professional degree.
\end{abstract}

Keywords: Cultivating base; Postgraduates with professional degree; university-enterprise cooperated

\section{Introduction}

In modern society, competition of science and technology not only reflects in the innovation of science and technology, but also in the transformation speed of scientific and technological achievements. As an important aspect of science and technology development, the universities play a vital role in the transformation of science and technology to productivity. At present, however, under the traditional postgraduate cultivating mode of our country, relation between research subject and enterprise are at a relative lower level, and relation between research results and actual production are still at a relative lower level. Therefore, a lot of scientific and technological achievements have little actual application value or unable to transform into practical productivity[1].

Based on the subject advantages of our school, we build an integration university-enterprise cooperated cultivating base of production, learning, research and application to accelerate the cultivation of professional degree postgraduate. The establishment of cultivating base entitles postgraduates to get guidance from experienced high level professional technicists. At the same time, by communicating and learning from the employees, the postgraduates knew the latest and most professional production information of the industry, and become familiar with the production management experiences which greatly training their 
innovation and practical abilities in practical work[2].

\section{Practical educating system completed at the base}

The establishment of universityenterprise cooperated cultivating base for postgraduates with professional degree mostly aims at compensating for the lack of practical and innovation abilities of postgraduates with professional degree under our traditional mode. Therefore, we introduce the "Two Stages" education and "Two tutors" cultivation system. The socalled "Two Stages" education, which is based at the characteristic of engineering postgraduates, divide the postgraduates cultivating process into two stages, i.e., theoretical knowledge leaning and base practice cultivation. "Two tutors" system, under "Two stage" education mode, changes the situation of only one tutor in traditional cultivation, and sets up two tutors in university and enterprise who are directly responsible for professional postgraduate. At the university, qualified professor of our school acts as a tutor who is mainly responsible for the postgraduate's theoretical knowledge learning. The tutor gives postgraduates academic guidance when they encounter theory problems in the topic study, and participates, presides over the thesis subediting and defense activities, etc. While experienced technicist possessing middle or senior technical title in the relevant enterprise acts as a tutor who is mainly responsible for the postgraduate's practical education in the cultivating base. The tutor gives postgraduates guidance about engineering problems in subject practice, afford practice site and funds, and participates, presides over the thesis subediting and defense activities with the university tutor[3].
As the professional part of practical experience accumulation and practice and innovation abilities advancement of professional postgraduates, the practice stage is key to professional postgraduate cultivation. In the university-enterprise cooperated cultivating base, the education tasks of postgraduates mainly include the following aspects:

(1)The enterprise culture learning links.

(2)The basic practical skill education links.

(3)The postgraduates' degree thesis research links.

(4)Other educational activities at the base.

\section{The enterprises thesis selecting and proposing}

Because the professional postgraduate in the cultivating base really participate in the enterprise actual production, the research content is inevitably derived from the actual problems of scientific research project, the technical bottleneck and process improvement in enterprise production, namely that the enterprises propose and select the thesis topic according to scientific research projects in their own actual production[4]. It is certainly that the enterprise will invest a lot of money and experienced technicians for the scientific research projects which need to be transformed, developed, or popularized, to solve funds shortage in university practice and ensure that the postgraduates in the first production line to accept the guidance of the most outstanding technicists in the industry. Meanwhile, the students go directly to the forefront of enterprise production to participate in the topic research and project development, which will greatly enrich the practice experience and practical ability of the postgraduates[5].

After thesis topic is determined, the university and the enterprise agree on the 
cultivating program, plans and evaluation standard for postgraduates based on the subject requirements for the post skills, enterprise personnel standards and basic qualities for postgraduates. Except the basic compulsory course of all professional postgraduates, the course system of every postgraduate should reflect the consistency, flexibility, self regulation.

\section{Introducing enterprise into the academic activities}

(1)Professors, scholars and experienced experts are invited regularly to give academic reports and experience exchanging meeting, etc.. Their profound knowledge and rich experience are applied, on the one hand, to answer and guide the theory and technology problems the postgraduates encountered in practical work, on the other hand, to educate and affect the postgraduate through their own academic and experience.

(2)Organizing the postgraduates, enterprise tutors and related technicists monthly to hold seminars to report the research progress of the subject, and share practical experience in the research, in which the practical problems that the postgraduates encountered are studied. The concrete forms of seminars should be flexible, and can be held in various forms such as speeches, free discussion and ask each other questions among the postgraduates.

(3)The base holds scientific research achievement exhibition of the postgraduates every year, the achievements being displayed can be in various forms of real objects and PPT display. The postgraduates and enterprise tutors vote to select the excellent works, and award the material rewards for the outstanding achievements.

(4)Practical innovation matches are carried out regularly, in which the contestants are postgraduates in teams. The competing works requires not only the demonstration of the design program, but also the physical model. Special attention should be paid to the works design innovation, the applicability of the final works and cooperation ability of the team members in the works selection.

\section{Base management}

(1)On the basis of mutual benefit, the university and the enterprise negotiate and establish the professional postgraduate degree cultivating base through scientific research cooperation, achievements sharing. After the agreement, the concrete program will be handed to the relevant departments to examine and approve.

(2)Considering base construction and postgraduate education as a link, the university and the enterprise are in close cooperation to complete technical research, production process improvement and other projects.

(3)It is necessary to establish the postgraduate subject group. Group members organize experience exchange meetings regularly. The postgraduates apply knowledge to analysis and demonstrate the actual case on their own project, share their experience in the meeting. The tutors guide the postgraduates to think actively depending on the postgraduates' mentality to cultivate the abilities of innovation and solving practical problems.

(4)The censorship of postgraduate attendance and the project progress should be strict, the tutors and management committee monthly assign special personnel to check postgraduates work progress.

(5)The management of professional graduate should be normalized, 
postgraduates need to report their practice work on paper to management committee at every stage, mainly including practice application, safety responsibility undertaking, attendance, practice reports, interim report, practice feedback forms and final postgraduate thesis.

(6)The base should invite university professors, enterprise experts and senior technicists to hold academic reports, experience exchange meetings, technical seminars and problem solving conferences, which are the complement of the base conventional cultivation[3].

(7)The postgraduates are encouraged to develop innovative consciousness and ability. The postgraduates achievements exhibition and innovation practice contest are carried out every year, and the postgraduates with good performance will be rewarded.

\section{Conclusion}

China's traditional postgraduate cultivating modes usually pay more attention on the theory knowledge learning. The comprehensive qualities of postgraduates, especially the practice ability and innovation ability are lacked badly. Based on the successful experience of postgraduates cultivation at home and abroad, our school has changed the shortage of the traditional cultivating mode on the postgraduates' practice and innovation abilities, through establishing the university-enterprise cooperated cultivating base. In the construction of the base educating system, three basic education parts, enterprise culture learning, education of basic practical skills and postgraduate degree thesis research, have been established. And various educating activities, such as the academic lectures, technology seminars, practice innovation contests, are introduced to develop the postgraduates' comprehensive quality based on enhancing the practical and innovative abilities of the postgraduates of solving the actual problems.

\section{Acknowledgments}

This work was financially supported by Shandong Province Graduate Education Innovative Projects (SDYY11063).

\section{References}

[1] J JYin , Y H Hu . Approach Analysis on the Establishment of UniversityEnterprise Cooperated Union by Universities [J]. China Electric Power Education, 2011, 197(11): 25-26.

[2] Yang H. Exploration on the Construction of Engineering Graduate Training Base of Two-Sections Innovational Mode [J]. Journal of Henan Institute of Science and Technology, 2010, 4: 15-17.

[3] Jiang Y. On "4+1" Education Mode of Training Application-Oriented Talents for City Planning [J]. Journal of Architectural Education in Institutions of Higher Learning, 2011, 20(3): 25-29.

[4] Zheng J Y, Chen Q Q, Liu M, etc.. Co-construction of the Postgraduate Innovation Base and UniversityEnterprise Cooperation Common Development [J]. China Electric Power Education, 2011, 188(1): 4446.

[5] Liu D G, Chen K Z. Exploration on "Order+Joint" Talents Cultivation Mode of Higher Vocational Schools, $[\mathrm{J}]$. Vocational and Technical Education, 2011, 14(38): 51-54. 